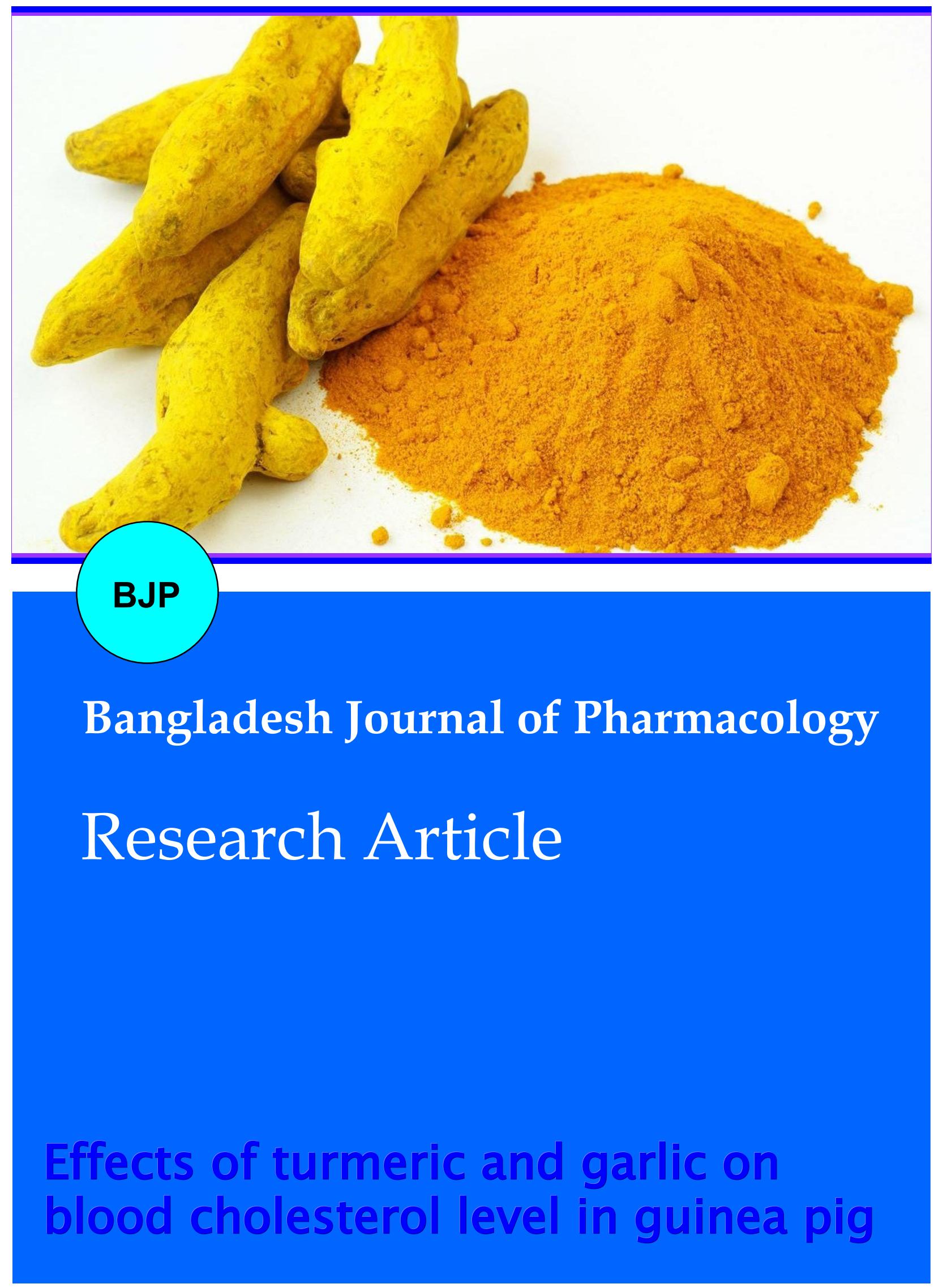


Abstracted/indexed in Academic Search Complete, Asia Journals Online, Bangladesh Journals Online, Biological Abstracts, BIOSIS Previews, CAB Abstracts, Current Abstracts, Directory of Open Access Journals, EMBASE/Excerpta Medica, Google Scholar, HINARI (WHO), International Pharmaceutical Abstracts, Open J-gate, Science Citation Index Expanded, SCOPUS and Social Sciences Citation Index;

ISSN: $1991-0088$

\title{
Effects of turmeric and garlic on blood cholesterol level in guinea pig
}

\author{
Muhammad Mustafizur Rahman Chowdhury, Shah Md. Moinuddin and Md. Kamrul \\ Islam
}

Department of Physiology, Bangladesh Agricultural University, Mymensingh 2202, Bangladesh.

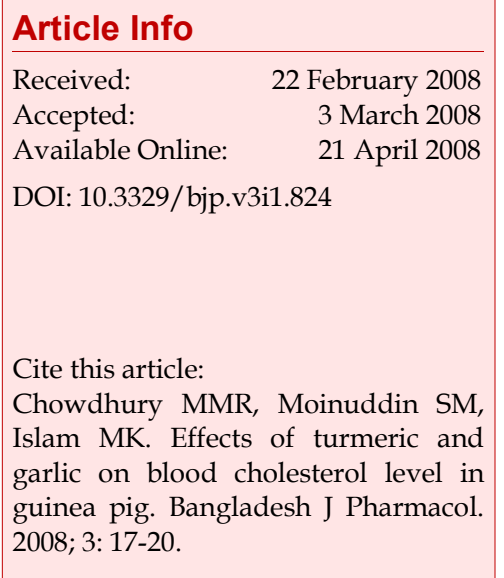

\begin{abstract}
This study has been attempted to investigate the effects of garlic and turmeric on blood cholesterol level. A total of 20 male guinea pigs of unknown breed weighing 400-600 g were randomly divided into four equal groups (A, B, C, D) with free access to food and water for 30 days. Three groups of animals (B, $\mathrm{C}$ and D) were fed either with turmeric or garlic supplemented basal diet and were defined as treated groups while remaining one group (A) was fed only with basal diet and considered control group. The body weight increased significantly $(p<0.01)$ in all the animals with the advancement of age. The administration of turmeric or garlic or both reduced the blood cholesterol level of the animals significantly $(\mathrm{p}<0.01)$. At the end of the experiment, the animals were killed and liver was examined for gross and histological changes. Some gross lesions were identified in liver of treated animals but there were no histological changes.
\end{abstract}

\section{Introduction}

The problem of atherosclerosis, thrombosis and myocardial infarction has recently increased many folds in urban population of Bangladesh (Zaman et al., 1981). Dietary factors play a key role in the development of various human diseases, including cardiovascular disease. It is a great challenge for scientists all over the world to make a proper use of garlic, turmeric and enjoy its maximum beneficial effect as it is the cheapest way to prevent cardiovascular disease. Considering these points, the present experiment has been taken into consideration with some objectives such as investigation of the effect of turmeric on serum cholesterol level, the effect of garlic on serum cholesterol level and combined effects of garlic and turmeric on serum cholesterol level.

\section{Materials and Methods}

A total of 20 male guinea pig of unknown breed weighing 400-600 g were randomly divided into four experimental groups (A, B, C, D) having five animals in each and were kept under a 12 hour light-dark cycle with free access to food and water. Water, green grass and wheat bran were allowed ad libitum for 30 days. The animals of all experimental groups were supplemented with either by turmeric or garlic at a dose rate of $4 \mathrm{mg} /$ day. Group A received a turmeric-free feed daily and treated as control group. At the same time, Group B was orally treated with a turmeric powder (Pran Brand of Bangladesh) at a dose of $4 \mathrm{mg} /$ day, Group C was fed with garlic oil tablet (supplied by the IPM laboratories, Department of Plant Pathology, Bangladesh Agricultural University, Mymensingh) at a dose of $4 \mathrm{mg} /$ day, 
Table I

Effects of turmeric and garlic on body weight and blood cholesterol level

\begin{tabular}{|l|ccccccc|}
\hline Group & $\begin{array}{c}\text { No. of guinea } \\
\text { pigs }\end{array}$ & \multicolumn{3}{c}{ Body weight $(\mathrm{g})$} \\
\cline { 2 - 8 } & & Day 1 & Day 15 & Day 30 & Day 1 & Day 15 & Day 30 \\
A & 5 & $500.0 \pm 5.8$ & $526.7 \pm 12.0$ & $616.7 \pm 8.8$ & $37.8 \pm 0.9$ & $44.4 \pm 3.8$ & $45.1 \pm 2.1$ \\
B & 5 & $480.7 \pm 3.0$ & $503.3 \pm 8.8$ & $588.3 \pm 4.4$ & $44.3 \pm 0.6$ & $42.0 \pm 1.7$ & $34.4 \pm 0.4$ \\
C & 5 & $461.7 \pm 6.0$ & $480.0 \pm 2.9$ & $566.7 \pm 4.4$ & $42.0 \pm 0.7$ & $40.5 \pm 1.2$ & $31.2 \pm 1.0$ \\
D & 5 & $460.3 \pm 2.6$ & $467.7 \pm 1.4$ & $535.0 \pm 2.9$ & $37.0 \pm 1.0$ & $33.4 \pm 1.1$ & $25.9 \pm 1.4$ \\
\hline
\end{tabular}

Data are mean \pm SE

Group D was fed with garlic oil tablet along with turmeric at a dose of $4 \mathrm{mg} /$ day. The animals were clinically observed and weighed weekly. Blood samples from all 20 selected animals were collected in test tubes and allowed to clot for 1 hour at room temperature. After 1 hour, the serum was taken in a set of centrifuge tube and was centrifuged at 3,000 rpm for $15 \mathrm{~min}$. The clear non-hemolyzed supernatant fresh serum was then carefully taken into a set of clean, dry, rubber stoppered, and sterilized glass vials. The blood cholesterol level was determined by enzymatic colorimetric test. After killing, 20 guinea pigs were examined for gross pathological lesions. At necropsy, gross tissue changes were observed, recorded carefully and representative tissue samples were preserved in $10 \%$ buffered formalin for histopathological studies as per standard procedure.

\section{Results}

Effects of diet on body weight were studied in four groups of animals which have been shown in Table I. It was evident that, in all of the groups, control and treated, the rate of increase in body weight was significantly higher in later half of the trial i.e., between $15^{\text {th }}$ and $30^{\text {th }}$ day of experiment than in between $1^{\text {st }}$ and $15^{\text {th }}$ day of experiment. Blood cholesterol levels of the animals supplemented with garlic, turmeric and both were decreased significantly $(p<0.01)$ between $15^{\text {th }}$ and $30^{\text {th }}$ day than $1^{\text {st }}$ and $15^{\text {th }}$ day of the experiment whereas the blood cholesterol level of the animals fed with normal diet was increased between $1^{\text {st }}$ and $15^{\text {th }}$ day than $15^{\text {th }}$ and $30^{\text {th }}$ day of experiment.

In post-mortem examination, no lesions were found in any other organs except liver. The lesions found were enlarged, pale, friable and congested liver. These were non-specific lesions and might be due to anesthesia and collection of blood directly from the heart prior to sacrifice.

In histopathology, no specific lesions were found as compared to the control group. The non-specific lesions were recorded in all the livers. The lesion includes central vein congestion, sinusoidal congestion, and slightly swollen hepatocytes (Figure 1).

\section{Discussion}

The body weight of the four groups of animals increased with the daily feed intake of the animals, suggesting the normal metabolic state of the animals. The blood cholesterol level of the animals fed with normal diet was increased. This increase was not statistically significant. It is due to feeds supplied to the guinea pigs and thus increased lipolysis stimulated by decreased glucose concentration in the blood.

The reduced cholesterol levels in turmeric-treated animals is a clear indication of stimulated bile fluid secretion as well as biliary cholesterol secretion and enhanced excretion of bile acids and cholesterol in feces which is almost similar to the report published by many authors (Rao et al., 1970; Patil and Srinivasan, 1971; Keshavarz, 1976; Soudamini et al., 1992; Soni et al., 1992; Hussain and Chandrasekhara, 1992; Hussain and Chandrasekhara, 1994).

It has also been found that, the animals fed with garlic supplemented diet have shown decreased cholesterol levels in blood. This finding is supported by the previous work (Chi et al., 1982; Yeh and Yeh, 1994). According to these authors, the reduced cholesterol level in these animals might be attributed to the capacity of garlic to reduce lipid content in arterial wall. This is also hypothesized that garlic might have depressed hepatic activities of lipogenic and cholesterogenic enzymes. This might also happen that increased excretion of cholesterol via feces by the effect of garlic is the cause of cholesterol decrease in blood of these animals. A significant decrease in cholesterol level in animals fed diet supplemented with garlic, turmeric and both, suggests the atheroprotective potential of these herbs. Garlic and turmeric are known to retard the development of atherosclerosis (Raj et al., 1998). 

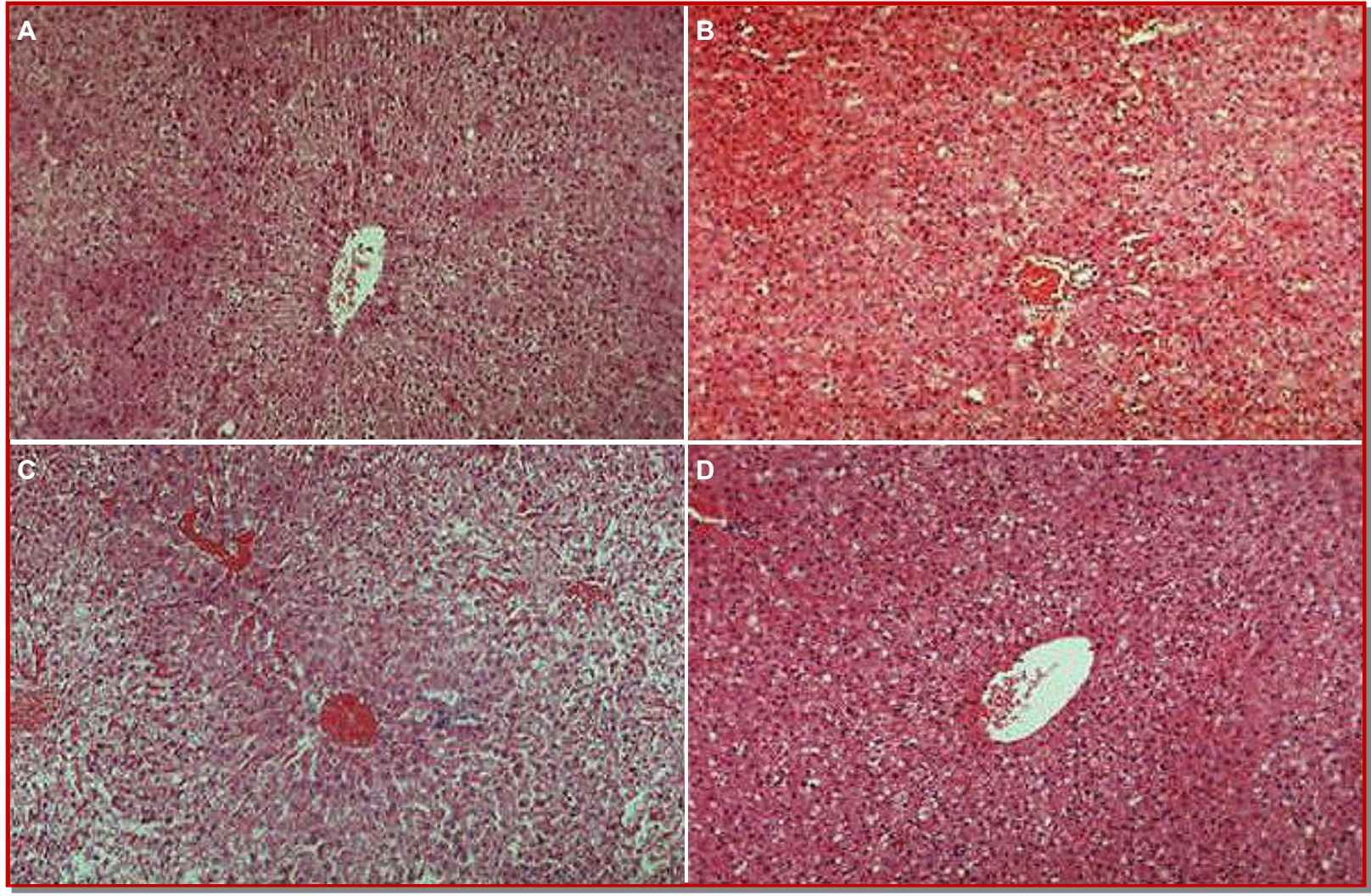

Figure 1: Histopathological section of liver of an adult guinea pig ( H \& E x 85) showing A) central vein congestion and sinusoidal congestion; B) treated with turmeric $4 \mathrm{mg} /$ day ( $\mathrm{H} \& \mathrm{E}$ x 85) showing central vein congestion and slightly swollen hepatocytes; C) treated with garlic $4 \mathrm{mg} /$ day ( $\mathrm{H} \& \mathrm{E} \times \mathrm{85}$ ) showing central vein congestion and slightly swollen hepatocytes; D) treated with both turmeric and garlic $4 \mathrm{mg} /$ day (H \& E x 85) showing central vein congestion and sinusoidal congestion

\section{Conclusion}

It has been found that oral administration of turmeric reduced cholesterol level significantly. Reduced level of cholesterol has also been found in animals treated with garlic through diet.

\section{Acknowledgement}

The authors are grateful to the Integrated Pest Management laboratory (IPM Lab), Bangladesh Agricultural University for their technical support in this research work.

\section{References}

Chi MS, Koh ET, Steward TJ. Effects of garlic on lipid metabolism in rats fed cholesterol or lard. J Nutr. 1982; 112: 241-48.

Hussain MS, Chandrasekhara N. Effect of turmeric on cholesterol gall-stone induction in mice. Indian J Med Res. 1992; 96: 288-91.
Hussain MS, Chandrasekhara N. Biliary proteins from hepatic bile of rats fed turmeric or capsaicin inhibit cholesterol crystal nucleation in supersaturated model bile. Indian J Biochem Biophys. 1994; 31: 407-12.

Keshavarz K. The influence of turmeric on cholesterol concentration of eggs and tissues. Poult Sci. 1976; 55: 107783.

Patil TN, Srinivasan M. Hypocholesteremic effect of turmeric in induced hypercholesteremic rats. Indian J Exp Biol. 1971; 9: 167-69.

Raj KS, Pillai KK, Balani DK, Hussain SZ. Antiatheros-clerotic effect of lipotab forte in cholesterol-fed rabbits. J Ethnopharmacol. 1998; 59: 125-30.

Rao DS, Sekhara NC, Satyanarayana MN, Srinivasan M. Effect of turmeric on serum and liver cholesterol levels in the rat. J Nutr. 1970; 100; 1307-15.

Soni KB, Rajan A, Kuttan R. Reversal of aflatoxin induced liver damage by turmeric and curcumin. Cancer Lett. 1992; 66: 115 $-21$.

Soudamini KK, Unnikrishnan MC, Soni KB, Kuttan R. Inhibition of lipid peroxidation and cholesterol levels in mice 
by turmeric. Indian J Physiol Pharmacol. 1992; 36: 239-43.

Yeh YY, Yeh SM. Garlic reduces plasma lipids by inhibiting hepatic cholesterol and triacylglycerol synthesis. Lipids 1994; 29: 189-93.
Zaman OA, Banoo H, Chowdhury S, Chowdhury ASR, Khaleque A. Effect of garlic oil on serum cholesterol and blood sugar level in adult human volunteers in Bangladesh. Bangladesh Med J. 1981; 10: 6-10.

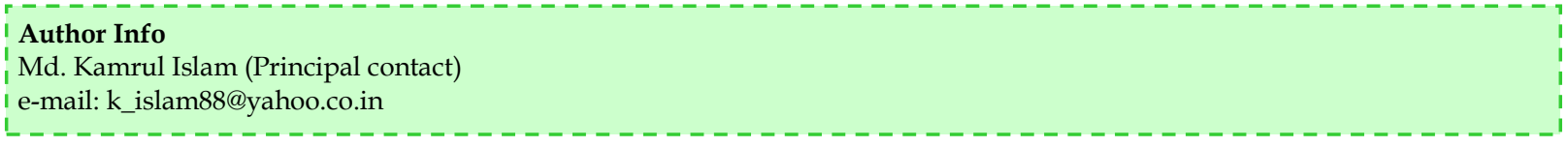

